Resenha

\title{
Saúde, trabalho e direito: uma trajetória crítica e a crítica de uma trajetória
}

VASCONCELLOS, Luiz Carlos Fadel de; OLIVEIRA, Maria Helena Barros de (Org.). Rio de Janeiro: Educam, 2011. 598p. ISBN: 978-85-7261-056-8

Este livro não trata de qualquer tema, nem de tema frequente, pois, embora verse sobre a relação Saúde e Trabalho, acrescenta a dimensão do Direito. Dessa forma, coloca fundamentalmente a questão da justiça e da injustiça no trabalho, ou seja, mostra que as condições de trabalho no mundo moderno, ao afetarem negativamente a saúde dos trabalhadores, são determinantes da produção da injustiça.

O paradoxo é evidente, pois, se "saúde é a condição para se andar a vida” (p. 36) e trabalho, o fator determinante para assegurá-la, como não se indignar diante da degradação e da precariedade das condições de trabalho, do adoecimento e das mortes que delas decorrem? O direito poderia, deveria regular esta situação paradoxal produzindo justiça. No entanto, a injustiça impera malgrado o direito, assim como, de certa forma, a regra de direito estabelecida no Brasil e determinadas práticas da "justiça” são vetores de injustiça, constituindo-se em mais um paradoxo.

A obra é, portanto, uma investigação para desvelar estes paradoxos, tendo como característica essencial trazer à tona elementos da história que explicam a produção das regras de direito e das práticas no campo da Saúde do Trabalhador (e do seu surgimento) sem perder de vista a análise crítica, como bem expressa o subtítulo "uma trajetória crítica e a crítica de uma trajetória”.

Nas 598 páginas do livro, os leitores são convidados a compartilhar o campo da Saúde, do Trabalho e do Direito ao longo dos seus 12 capítulos, cujos títulos resumem e antecipam a análise crítica dos temas, como é o caso exemplar do Capítulo 1, "As relações saúde-trabalho-direito e a justiça injusta" (com grifo pelo autor desta resenha).

Diante da amplitude e complexidade do livro e dos temas tratados, ao invés de apresentar e discutir cada capítulo individualmente, a fim de captar o que há de transversal, optou-se por um artifício cuja "chave" nos forneceram os próprios autores, ou seja, destacar-se-á a seguir o mais importante a partir das categorias "trajetória” (crítica) e "crítica” (da trajetória) para, em seguida, tratar das ausências antes de concluir mostrando a importância da obra.

\section{Trajetória}

Para analisar a longa trajetória em defesa da saúde no trabalho, os autores empreenderam profunda pesquisa bibliográfica a fim de buscar o entendimento histórico: da exploração do corpo dos trabalhadores pelos sistemas de produção capitalistas nas fases históricas (Capítulo 2); da própria constituição dos direitos do trabalho (Capítulo 3) e previdenciário (Capítulo 4); da instituição da OIT (Capítulo 5) e da saúde do trabalhador no SUS (Capítulo 9); dos movimentos de luta dos trabalhadores pela saúde (Capítulo 6) e do Movimento Operário Italiano - MOI (Capítulo 7), até a institucionalização da Saúde do Trabalhador no Brasil.

A descrição e apresentação das regras, normas e leis ocupam destaque nos primeiros capítulos (do $2^{ }$ao $5^{\circ}$ ), sendo antecedidas dos fatos históricos que permitem situá-las. De forma geral, os autores propõem leitura dos acontecimentos no mundo ocidental até chegar à realidade brasileira, onde são expostos e analisados. No Capítulo 3, por exemplo, para abordar a "regra trabalhista referente à saúde", percorre-se desde a revolução industrial até o surgimento do direito do trabalho, segue-se pela história da Consolidação das Leis do Trabalho até se chegar às Normas Regulamentadoras.

No entanto, não são apenas as normas que estão no centro da leitura histórica da trajetória. Os enfrentamentos entre trabalho e capital, apresentados ao longo de vários capítulos, permitem visualizar a importância dos movimentos de luta dos trabalhadores na produção da "política” em defesa da saúde, assim como os mecanismos de dominação e de controle utilizados pelo capital e por outros atores (como a Igreja, por exemplo), que são "dissecados" pelos autores. A história narrada pelos autores sobre a criação da OIT é exemplar.

No longo e rico capítulo sobre os movimentos de luta pela saúde, os autores resgatam: os movimentos durante o período da revolução industrial na Inglaterra, dos primórdios do sindicalismo e do surgimento do direito do trabalho; as lutas nos Estados Unidos no século XIX; o anarquismo no Brasil e as primeiras lutas dos operários (as principais greves 
no início do século XX); o período Vargas e da Guerra Fria até as lutas pela saúde iniciadas no final dos anos 1970, chegando, por fim, aos movimentos emblemáticos contra o benzeno, o amianto, a silicose e as LER/DORT.

O MOI é destacado por sua importância no desenvolvimento do campo da Saúde do Trabalhador no Brasil. São discutidos os antecedentes históricos, desde o século XIX, na origem das lutas operárias na Itália, dos eventos políticos que marcaram o século XX, sobretudo da influência de Gramsci, até o surgimento do MOI nos anos 1960. O protagonismo dos principais atores, entre eles Ivar Oddone, assim como os princípios do movimento sintetizados no lema "a saúde não se vende, nem se delega" (p. 388) são então abordados.

A trajetória descrita na obra chega até a constituição e instituição da Saúde do Trabalhador no SUS. São discutidos diversos eventos importantes, desde a constituição do Departamento Intersindical de Estudos e Pesquisas de Saúde e Ambientes de Trabalho (ao final dos anos 1970), a realização das três conferências de saúde do trabalhador (1986, 1994, 2005), o surgimento dos primeiros programas de saúde do trabalhador, a criação do Centro de Estudos em Saúde do Trabalhador e Ecologia Humana da Fundação Osvaldo Cruz até a Institucionalização da Saúde do Trabalhador após a Constituição de 1988.

\section{Crítica}

Se a leitura histórica nos transporta até as leis e normas que nos governam, os "modelos" vigentes, as instituições e seu funcionamento atual, a análise crítica baseada no referencial teórico marxista mostra, de um lado, sua face cachée, seus limites, suas contradições e, de outro, aponta para possibilidades e caminhos para sua superação.

No tocante às normas trabalhistas (Capítulo 3), a crítica se dirige ao próprio contrato de trabalho, que não prevê a garantia à saúde, assim como demonstra que as normas regulamentadoras são insuficientes, imperfeitas, para a efetiva prevenção. Quanto à legislação previdenciária (Capítulo 4), os autores mostram a perda do sentido da lei ao tentar reparar o que se perdeu: a saúde. Enfatizam a contradição maior disso, isto é, o fato de ser considerada como conquista dos trabalhadores (sic), "mas após perder sua saúde e sua vida” (p. 166).

Necessariamente, a análise crítica sobre o campo da saúde do trabalhador e sua institucionalização tem espaço importante no texto (Capítulos 8 a 10), uma vez que os autores atuam/atuaram nos serviços de saúde. Sua crítica ganha, portanto, legitimidade por vir de "dentro": das disputas envolvidas na cons- trução da saúde do trabalhador no SUS, que limitam sua efetividade, ou dos fatores que explicam a fragilidade da rede de serviços de saúde do trabalhador que "não enreda" (como sugere o título do capítulo).

Na crítica ao modelo de "desenvolvimento sustentável" (Capítulo 11), os autores mostram que a ideia de "sustentabilidade" é apropriada e utilizada pelo capital para sua "expansão permanente e ilimitada" (p. 493), favorecendo, de certa forma, a marginalização da questão do trabalho e da saúde dos trabalhadores no debate social sobre o desenvolvimento. Dirigem crítica também contra as políticas no âmbito da Saúde Pública que desconsideram a categoria trabalho, embora esta se constitua em "um fator complexo de determinação social dos problemas de saúde das mais diversas ordens, nos mais diversos grupos populacionais e na pluralidade territorial onde a vida ocorre” (p. 494). O título do capítulo resume bem tais contradições, ou seja, "Relações saúde-trabalho fora de foco: o desenvolvimento insustentável".

Apesar do cenário difícil, da expansão danosa do capital, do recuo atual dos movimentos sociais, da fragilidade institucional e regulamentar, do modelo de desenvolvimento adotado, os autores vislumbram a possibilidade de mudança que passa necessariamente pelo movimento de resistência dos trabalhadores e, portanto, a importância de determinada "praxis" educativa (Capítulo 12). Tornar os trabalhadores "intelectuais orgânicos" a partir de sua educação, cujo princípio formativo básico é o trabalho a partir das ideias de Marx e Gramsci, ou seguindo a pedagogia da mudança de Paulo Freire é o meio que se abre para a mudança da sociedade e a defesa da Saúde do Trabalhador.

\section{Necessidade de continuar a crítica da trajetória...}

Evidentemente que existem ausências no texto, como não poderia deixar de ser em obra de tamanha envergadura. A leitura do texto nos instiga, no entanto, a analisar e refletir sobre o campo e nossa prática, enfim, sobre a necessidade de estender a crítica da "trajetória", uma vez que somos guiados pela indignação diante da injustiça no trabalho. Como diz Vasconcellos, "a indignação é a rebelião mais poderosa da condição humana [...] e indignação é do senso comum no que tange à doença e à morte no trabalho" (p. 79).

Assim, por que não acrescentar alguns aspectos à discussão da "imperfeição da regra trabalhista referente à saúde"?

Nesse sentido, podemos chamar atenção para a ausência da análise e crítica da organização tripartite no Brasil que, por meio da Comissão Tripartite instituída pelo Ministério do Trabalho e Emprego (MTE), é responsável pela produção de normas regulamenta- 
doras. Tal processo está na origem da elaboração de normas, por definição imperfeitas, uma vez que seu resultado depende da negociação social. De certa forma, o capital controla a produção das normas, assim como define o que se pode fiscalizar e, portanto, controla a própria ação da auditória fiscal do MTE.

Outro aspecto não tratado pelos autores merece pequeno comentário. O "grau de imperfeição" da norma poderia ser obtido por meio de comparação com as normas de outros países, oriundas das mesmas convenções da OIT, o que permitiria visualizar as "escolhas" feitas e as limitações que provocam para a prevenção em nosso país.

Não seria, assim, esta obra um convite à análise e à crítica das demais instituições do campo?

\section{Sobre a importância do livro}

No momento atual, no qual o pacto pelo desenvolvimento em nosso país parece deixar de lado seus impactos sobre a sociedade e, em especial, sobre a saúde dos trabalhadores, a análise da trajetória e sua crítica proposta na obra mostram de forma decisiva a importância dos movimentos dos trabalhadores na produção da política e, consequentemente, do direito. Diante do processo, em vigor, de subjetivação do "fim do conflito entre capital e trabalho", usado não apenas para a defesa do desenvolvimento atual no país, mas, sobretudo, para expansão e perpetuação do capital, recolocar o papel do conflito no centro, demonstrando sua característica incontornável para produção de sociedade e do direito, é essencial para a perpetuação da vida. Daí a contribuição maior da obra.

Entre os méritos do livro, certamente está a qualidade de sua redação, que é suficientemente clara para favorecer a leitura, mas, ao mesmo tempo, refinada e erudita.

Como não citar uma das passagens que bem reflete a beleza do texto e a profundidade do pensamento dos autores:
Justiça justa nas relações saúde-trabalho seria aquela que fosse aplicada àquilo que nos indigna quando somos sujeitos observadores da realidade e que fosse aplicada àquilo que nos submete e humilha quando somos sujeitos observados. (p. 78)

A simplicidade e objetividade do texto o tornam instrumento de formação dos sujeitos e de emancipação dos atores sociais. Pode-se afirmar que foi projetado como tal, isto é, como ferramenta para a transformação dos atores e da sociedade.

Trata-se, por outro lado, de obra de referência para a prática, fruto da reflexão e da análise aprofundada de profissionais que passaram pelos serviços e cujo objetivo foi compreender o contexto da prática para aumentar sua margem de ação e produzir justiça no trabalho (ou ao menos diminuir a injustiça). Ter consciência dos próprios limites, dos impedimentos institucionais para a ação pública, da complexidade da luta de classes diminui o sofrimento e aumenta a possibilidade de agir de forma inteligente.

Enfim, se a compreensão crítica da trajetória serve, pode-se dizer que, em última instância, serve para se redesenhar o futuro. Mostram-nos os autores que a análise crítica deve anteceder a ação, ou seja, a trajetória futura, capaz de promover a justiça nas relações saúde-trabalho, deve ser construída a partir da reflexão e da análise crítica.

Trata-se de questão urgente, pois, como afirma Vasconcellos:

$$
\begin{aligned}
& \text { as relações saúde-trabalho-direito, no curso da his- } \\
& \text { tória, são indignas, e a condição humana não foi } \\
& \text { capaz de modificá-las, porque não ousou fazê-lo. } \\
& \text { Indignamo-nos, até hoje, aquém da necessidade de } \\
& \text { transformá-las. Eis aí um belo desafio" (p. 79) }
\end{aligned}
$$

Por que não se juntar e aceitar então o desafio proposto por Vasconcellos?

A leitura do livro pelo maior número de sujeitos pode ser um passo decisivo para reescrevermos coletivamente esta trajetória, ou seja, a história do movimento pela saúde dos trabalhadores.

José Marçal Jackson Filho

Centro Estadual do Rio de Janeiro da Fundacentro Rio de Janeiro, RJ, Brasil.

E-mail: jose.jackson@fundacentro.gov.br 